\title{
Identifying the link between MBRs' key operating parameters and bacterial community: a step towards optimized leachate treatment
}

\author{
Authors: \\ Dany Roy ${ }^{a}$, Jean-François Lemay ${ }^{c}$, Patrick Drogui ${ }^{a,{ }^{*}},{ }^{2}$ Rajeshwar D. Tyagi ${ }^{a}$, Dany Landry $^{b}$, \\ Mohamed Rahnic \\ a INRS, 490, rue de la Couronne, Québec, Qc., Canada, G1K $9 A 9$ \\ ${ }^{b}$ Englobe Corp., 505 Boul. de Parc Technologique, Québec, Qc., Canada, G1P 4S7 \\ ${ }^{c}$ CNETE, 2263, Avenue du Collège, Qc, Canada, G9N 6V8 \\ * patrick.drogui@ete.inrs.ca
}

\begin{abstract}
:
A MBR treating compost leachate was studied in order to link the operating parameters (solid and hydraulic retention time) to contaminant's specific bacterial catabolic activity. In this context, a lab-scale aerobic membrane bioreactor was operated for 200 days, at solid retention times (SRT) of 30 and 45 days and four different contaminant load rates. Results showed that increasing the food to microorganism ratio (F/M) by increasing the contaminant load rates lessened the selectivity pressure, which allowed the proliferation of subdominant operational taxonomic units (OTU) (relative abundance $>3 \%$ ) that were otherwise inhibited by highly adapted dominant OTUs (relative abundance $>10 \%$ ). Subsequently, increasing the SRT resulted in a lower species richness and the selection of two dominant types of bacteria: 1) genera with low growth rates that feed on non-limiting substrates or substrates with few competitors, and 2) genera with metabolisms that are highly specific to the available substrates and that can outcompete the other genera by using the substrate more efficiently. The bacterial population evolution observed during this study suggests that the mixed liquor population diversity and structure can be modulated with the operating conditions for the bioenhancement of contaminant specific catabolic activity. Identified dominant and subdominant genera were linked to the SMBR's $\mathrm{NH}_{4}^{+}$and $\mathrm{COD}$ removal performances. Interestingly, nitrification performances were unaffected by the organic load rate and the Nitrosomonas relative abundance.
\end{abstract}

Keywords: Membrane bioreactor, Microbial community, Composting leachate, Solid retention time, Sequencing, Nitrification 


\section{List of abbreviation}

$\begin{array}{ll}\text { BOD5 } & \text { Biological oxygen demand over a period of } 5 \text { days } \\ \text { COD } & \text { Chemical oxygen demand } \\ \text { DO } & \text { Dissolved oxygen } \\ \text { F/M } & \text { Food to microorganism ratio } \\ \text { HRT } & \text { Hydraulic retention time } \\ \text { MBR } & \text { Membrane bioreactor } \\ \text { MLVSS } & \text { Mixed liquor volatile suspended solids } \\ \text { OTU } & \text { Operating taxonomic units } \\ \text { PAH } & \text { Polyaromatic hydrocarbons } \\ \text { PCOA } & \text { Principal component analysis } \\ \text { SMBR } & \text { submerged membrane bioreactor } \\ \text { SRT } & \text { Solid retention time } \\ \text { TMP } & \text { Transmembrane pressure }\end{array}$




\section{Introduction}

With the ever increasing amount of waste produced on a global scale due to industrial and commercial growth, leachates generated from waste management facilities, such as waste composting facilities, have become a significant threat to the preservation of nearby water resources. These leachates are characterized by high concentrations of both bio-refractory organic substances (low $\mathrm{BOD}_{5} / \mathrm{COD}$ ratios) and ammoniacal nitrogen (Renou et al. 2008). Depending of the type of waste managed at a particular facility, leachates can also contain hazardous concentrations of heavy metals, phosphorus, and micropollutants (Ahmed and Lan 2012, Ramakrishnan et al. 2015, Roy et al. 2019). Owing to the potential risk posed by this heavily polluted wastewater, environmental regulatory agencies are forced to implement increasingly stringent regulations regarding the environmental disposal of these treated wastewaters(Ahmed and Lan 2012).

To meet these stricter water quality standards, membrane bioreactors (MBR) systems are increasingly being recognized as the process of choice for the treatment of high-strength wastewater such as waste leachates (El-Fadel et al. 2018, Roy et al. 2018). MBRs are distinguished from conventional activated sludge systems (CAS) by the use of a micro/ultrafiltration membranes to separate the biomass from the effluent (Ng and Kim 2007). In addition to eliminating the need for large settling tanks, the membrane provides an independent control over the hydraulic retention time (HRT) and the solid retention time (SRT). Therefore, biomass can be kept in the system regardless of its ability to form flocs and settle.

MBRs' treatment performances mostly depend on key metabolic activities of the mixed liquor microbial community ( $\mathrm{Hu}$ et al. 2012). This community development is the result of an enrichment of specific microorganisms either originally present in the wastewater to be treated or from inoculated in the reactor. Under the controlled environment of the MBR, the most adapted members are selected to give rise to a resilient and trophically adapted population (Köchling et al. 2015). The community's diversity and structure depend on a certain set of influencing factors that are summarized in Figure 1. Amongst these factors, the most commonly discussed in the scientific literature are the process design (HRT, SRT, oxic conditions)(Xue et al. 2015), the influent composition and variability (Hu et al. 2012), and the temperature variations (short and long term variations)(Gonzalez-Martinez et al. 2018).

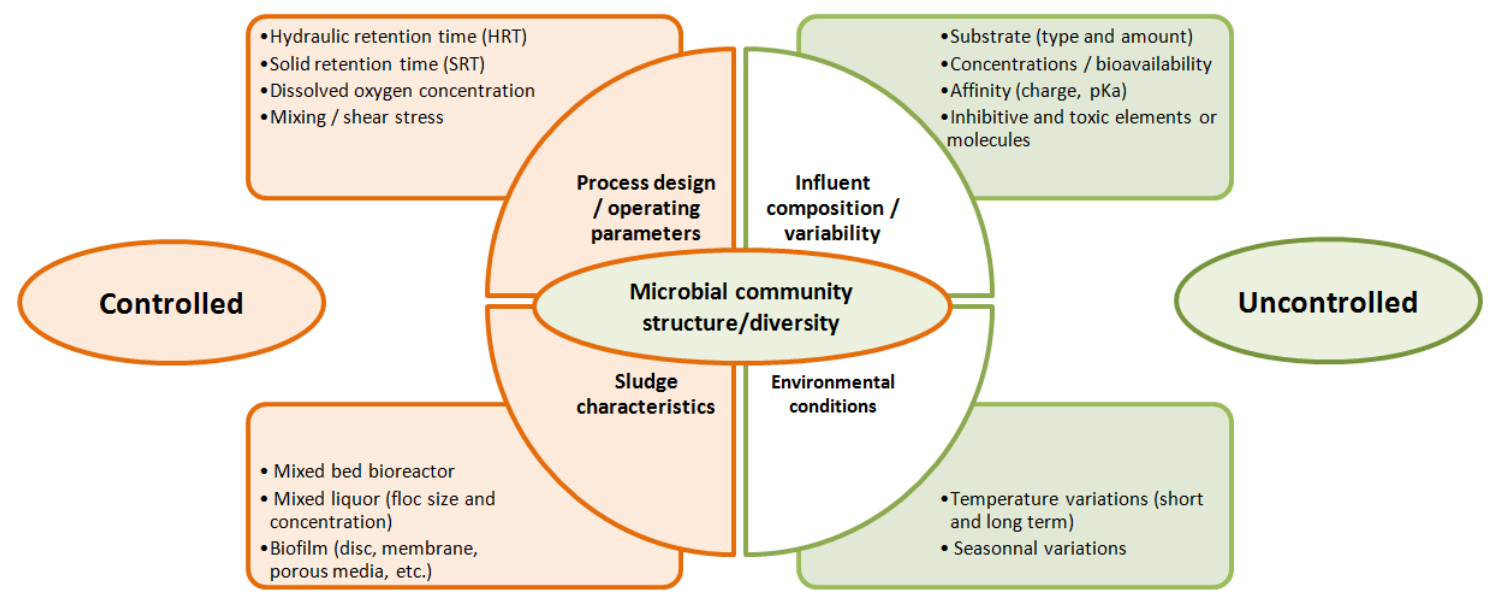

Figure 1 Factors influencing the microbial community structure and diversity in wastewater biotreatment processes 
MBR's complete control over the SRT is reported to have two main advantages when developing a wastewater specific microbial community: 1) a low-abundance of microorganisms from the wastewater can act as a microorganism seeder pool and become enriched in the mixed liquor since they are maintained in the reactor(Köchling et al. 2015), and 2) slow-growing microorganisms with substrate-specific metabolisms can be enriched and compete with $r$ strategist heterotrophic microorganism ubiquitous in the marine environment and in industrial/municipal wastewaters(Canziani et al. 2006). While increasing efforts are being deployed to identify the species populating environmental wastewater treatment bioprocesses, relating MBRs' operating parameters (HRT and SRT) to their treatment performances and to the key metabolism of the mixed liquor's microbial community remains challenging (El-Fadel et al. 2018, Hu et al. 2012, Xue et al. 2015, Duan et al. 2009). Understanding the evolution of the mixed liquor's operational taxonomic units (OTU) under different operating conditions is of interest for MBRs' design, operation, and control, in order to promote specific metabolic activities for the treatment of targeted contaminants.

This study was segmented in three main objectives. First, the bacterial population structure and diversity of MBR's mixed liquor fed with synthetic and real composting leachates were analyzed in order to determine how complex substrates can influence a bacterial population. The second objective was to characterize the effect of the SRT and the contaminant load rates on bacterial communities' diversity and structure at the phylum and genus level in a lab-scale submerged MBR (sMBR) treating composting leachates. In this context, the sMBR was operated using real leachate with a constant composition at SRTs of 30 and 45 days and HRTs of 12, 24, 36 and 48 hours. Finally, the third objective was to relate the structure of bacterial community to the treatment performances of the reactor. Due to their frequent detection in leachates above the standard limits, the following contaminants were studied: $\mathrm{COD}, \mathrm{BOD}_{5}$, and $\mathrm{NH}_{4}{ }^{+}$, and total phosphorus. Furthermore, the microbial population evolution during the transition between synthetic and real leachate having a similar composition was assessed.

\section{Material and methods}

\subsection{Lab-scale submerged membrane bioreactor}

The lab-scale sMBR used in this study is shown in Fig. $2 a$ and $2 b$. 


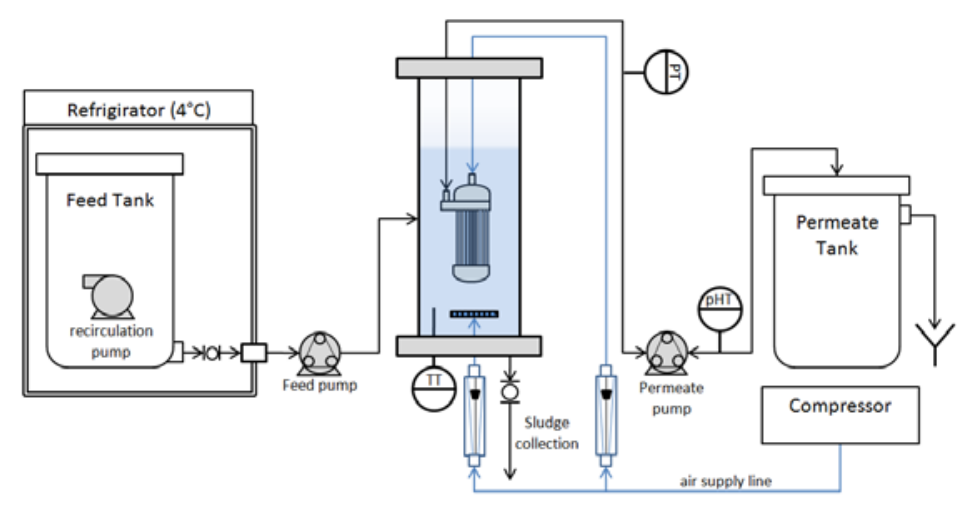

(a)

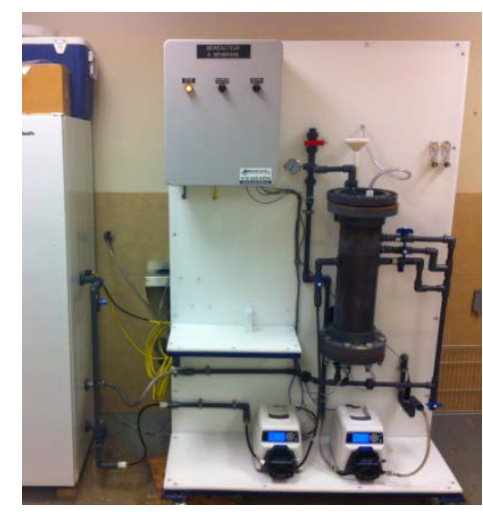

(b)

Figure 2 (a) PFS of the lab-scale submerged membrane bioreactor and (b) Picture of experimental set-up

The composting leachate (feed) was kept in a $50 \mathrm{~L}$ polyethylene tank placed in a refrigerator at $4^{\circ} \mathrm{C}$ in order to avoid any biological activity that could alter its composition prior to treatment. The $10 \mathrm{~L}$ reactor was made of a $146.33 \mathrm{~mm}$ I.D. clear PVC tube (schedule 80). The leachate was fed into the reactor through a side port using a peristaltic pump (Masterflex, model \#7528-10). The retention time in the tube between the feed tank and the reactor was sufficient for the wastewater temperature to reach room temperature $\left(20 \pm 1^{\circ} \mathrm{C}\right)$ before it was fed to the reactor. An ultrafiltration hollow-fiber membrane module (Zee-Weed, ZW-1) was used. The ZW-1's specifications are presented in Table 1. The treated leachate (permeate) was collected in a $20 \mathrm{~L}$ polyethylene tank and emptied on a daily basis.

Table 1 Zee-Weed ZW-1 membrane module specifications

\begin{tabular}{|l|l|}
\hline Nominal pore diameter $(\mu \mathrm{m})$ & 0.04 \\
\hline Fiber diameter $(\mathrm{mm})$ & 2 \\
\hline Membrane surface area $\left(\mathrm{m}^{2}\right)$ & 0.047 \\
\hline Max. transmembrane flux $\left(\mathrm{L} \mathrm{m}^{-2} \mathrm{~h}^{-1}\right)$ & 32 \\
\hline
\end{tabular}

The permeate flow-rate (filtration: $300 \mathrm{~s}$, flux $7.4 \mathrm{~L} \mathrm{~m}^{-2} \mathrm{~h}^{-1}$; backwash: $20 \mathrm{~s}$, flux $46.4 \mathrm{~L} \mathrm{~m}^{-2} \mathrm{~h}^{-1}$ ) was maintained constant during each experiment by controlling the vacuum applied at the membrane ( 5 to $50 \mathrm{kPa}$ ) with a peristaltic pump (Masterflex, model \#7528-10). To prevent the accumulation of a cake layer at the membrane surface, filtration/backwash cycles were applied and air was introduced between the membrane fibers through a perforated pipe built in the module ( $2.5 \mathrm{~L}$ air $\mathrm{min}^{-1}$ ). Membrane module cleaning was conducted when the transmembrane pressure (TMP) reached $-50 \mathrm{kPa}$. The cleaning procedure was the following: 1 ) $3 \mathrm{hrs}$ of dynamic oxidative cleaning (in a close loop recirculation) with a $1000 \mathrm{mg} \mathrm{L}^{-1}$ active chlorine solution $(\mathrm{NaOCl})$, 2) $5 \mathrm{~min}$ of rinsing with distillated water, 3) $1.5 \mathrm{hrs}$ of dynamic acidic cleaning (in a close loop recirculation) with a $3 \mathrm{~g} \mathrm{~L}^{-1}$ citric acid solution, and 4) $5 \mathrm{~min}$ of rinsing with distillated water.

The sMBR was operated in oxic conditions (D.O. $=6-7 \mathrm{mg} \mathrm{O}_{2} \mathrm{~L}^{-1}$ ) at room temperature $\left(20 \pm 1^{\circ} \mathrm{C}\right.$ ). Compressed air was introduced through a perforated tube placed at the bottom in the reactor $\left(2.5 \mathrm{~L} \mathrm{~min}^{-1}\right)$ and arranged in such way as to create a homogeneous internal mixing of the reactor from the rising bubbles. SRT was controlled by collecting mixed liquor samples on a daily 
basis. HRT was controlled by adjusting the mixed liquor volume, and calculated by measuring the collected permeate and mixed liquor volume on a daily basis.

\subsection{Activated sludge growth and acclimation}

The timeline of the activated sludge growth and sMBR experiments is presented in Figure 3 . An initial sample volume of $40 \mathrm{~L}$ of mixed liquor, with a concentration of approximately $0.25 \mathrm{~g}$ mixed liquor volatile suspended solids (MLVSS) $\mathrm{L}^{-1}$, was taken from an aerated lagoon used for the treatment of leachates at a co-composting facility located in Quebec, Canada, and left to decant for $24 \mathrm{~h}$. Then, the supernatant was removed and solids were transferred in a $20 \mathrm{~L}$ batch aerated reactor filled with synthetic leachate. Then, over the duration of 4 weeks, the supernatant was replaced every week with $20 \mathrm{~L}$ of fresh synthetic leachate. In order to maintain an adequate concentration of substrate while increasing the concentration of the biomass in the mixed liquor, $22 \mathrm{~g}$ of ammonium acetate $\left(200 \mathrm{mg} \mathrm{NH}_{4}-\mathrm{N} \mathrm{L}^{-1}, 343 \mathrm{mg} \mathrm{C}_{\text {org L}} \mathrm{L}^{-1}\right)$ and $13.3 \mathrm{~g}$ of calcium propionate ( $247 \mathrm{mg} \mathrm{C}_{\text {org }} \mathrm{L}^{-1}$ ) were added every 3 to 4 days. After 4 weeks, the mixed liquor was introduced to the MBR and adapted to the reactor's condition for a period of 4 weeks. Then, over a period of 5 weeks, the synthetic leachate fed to the MBR was gradually substituted with real leachate. During the first 2 weeks, $25 \%$ of the synthetic feed was replaced with real leachate. Then, every week, $25 \%$ of the synthetic leachate was replaced with real leachate until its complete replacement. Finally, over a period of 21 weeks, 6 different combinations of 2 SRTs (30 and 45 days) and 4 HRTs $(12,24,36$, and 50 hours) were tested using real leachates, the composition of which is detailed at section 2.3.

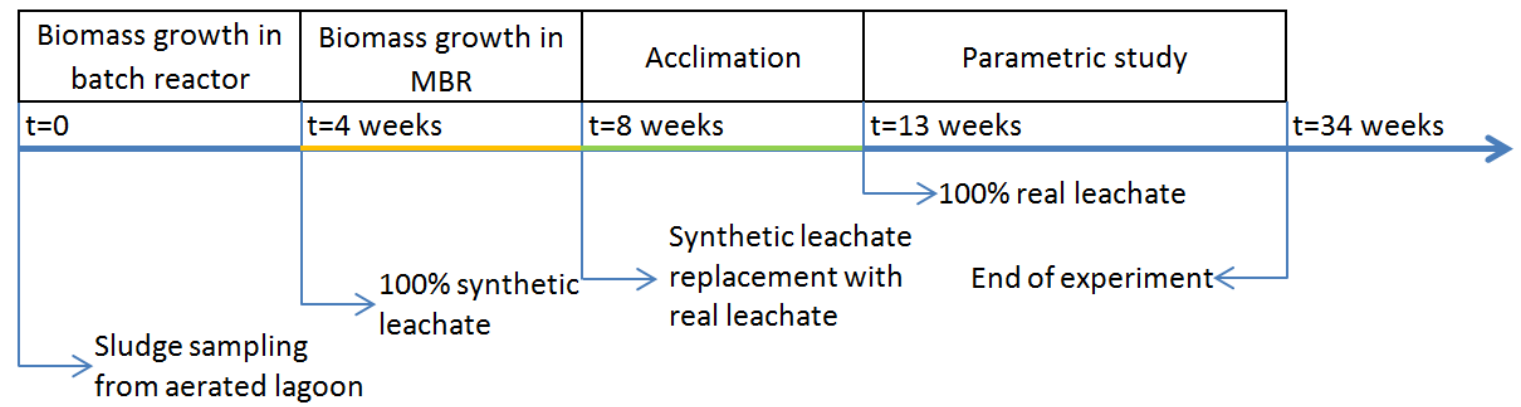

Figure 3 Activated sludge growth and sMBR experiments timeline

\subsection{MBR operating parameters}

The operating parameters of the sMBR corresponding to each of the mixed liquor samples collected for microbial population analysis are detailed in Table 2.

Table 2 sMBR's operating parameters corresponding to each mixed liquor sample collected for microbial population analysis

\begin{tabular}{|l|l|l|l|l|l|l|l|l|l|}
\hline Parameters & $\begin{array}{l}\text { Aerated } \\
\text { Lagoon }\end{array}$ & $\begin{array}{l}\text { MBR- } \\
\text { Synthetic }\end{array}$ & $\begin{array}{l}\text { Acclim. } \\
\mathbf{5 0 - 5 0}\end{array}$ & $\begin{array}{l}\text { Cond. } \\
\mathbf{\# 1}\end{array}$ & $\begin{array}{l}\text { Cond. } \\
\mathbf{\# 2}\end{array}$ & $\begin{array}{l}\text { Cond. } \\
\mathbf{\# 3}\end{array}$ & $\begin{array}{l}\text { Cond. } \\
\mathbf{\# 4}\end{array}$ & $\begin{array}{l}\text { Cond. } \\
\mathbf{\# 5}\end{array}$ & $\begin{array}{l}\text { Cond. } \\
\mathbf{\# 6}\end{array}$ \\
\hline Period length (d) & - & 28 & 7 & 50 & 21 & 22 & 20 & 21 & 28 \\
\hline Leachate treated & Real & Synthetic & $\begin{array}{l}50 \% \\
\text { synthetic, } \\
50 \% \text { real }\end{array}$ & real & real & real & real & real & real \\
\hline SRT (d) & unknown & 30 & 30 & 30 & 30 & 30 & 30 & 45 & 45 \\
\hline
\end{tabular}




\begin{tabular}{|l|l|l|l|l|l|l|l|l|l|}
\hline HRT (hrs) & 360 & 48 & 48 & 48 & 36 & 24 & 12 & 24 & 12 \\
\hline MLVSS $\left(\mathrm{mg} \mathrm{L}^{-1}\right)$ & 250 & 5810 & 3800 & 2680 & 3200 & 4080 & 6990 & 6790 & 8780 \\
\hline $\mathrm{NLR}\left(\mathrm{g} \mathrm{NH}_{4}-\mathrm{N} \mathrm{m}^{-3} \mathrm{~d}^{-1}\right)$ & 27 & 98 & 153 & 191 & 269 & 397 & 742 & 382 & 740 \\
\hline $\mathrm{OLR}\left(\mathrm{g} \mathrm{COD} \mathrm{m}^{-3} \mathrm{~d}^{-1}\right)$ & 310 & 800 & 1225 & 1514 & 1933 & 2477 & 5022 & 2342 & 3969 \\
\hline
\end{tabular}

The period length corresponds to the number of days during which the reactor was operated at the described conditions before the mixed liquor sample was taken. During the parametric study (Cond. \#1 to \#6), the duration of each experimental condition was at least 20 days in order to reach steady-state conditions. After 14 days of operation under the same operating conditions, samples were taken every day for 5 days. If the difference in COD and $\mathrm{NH} 4^{+}$removal rates between two samples taken within a 5-day interval was less than $5 \%$, then the SMBR was considered to be operating at steady-state. Otherwise, the sampling period was extended until that maximum 5\% difference was measured. The synthetic and real composting leachates' complete characterizations are presented in Table 3. In order to maintain a constant feed composition for each different tested condition during the parametric study, a $1 \mathrm{~m}^{3}$ leachate sample was collected and stored in a cold room at $4^{\circ} \mathrm{C}$. Then, the sMBR's feed tank was filled from that $1 \mathrm{~m}^{3}$ leachate sample.

Table 3 Synthetic and real leachates' characterization

\begin{tabular}{|l|l|l|l|}
\hline Parameter & Units & $\begin{array}{l}\text { Synthetic } \\
\text { leachate }\end{array}$ & $\begin{array}{l}\text { Composting } \\
\text { leachate }\end{array}$ \\
\hline Alkalinity & $\left(\mathrm{mg} \mathrm{CaCO}_{3} \mathrm{~L}^{-1}\right)$ & 3000 & $3062-3365$ \\
\hline Ammoniacal nitrogen & $\left(\mathrm{mg} \mathrm{NH}_{4}-\mathrm{N} \mathrm{L}^{-1}\right)$ & 400 & $398-413$ \\
\hline $\mathrm{BOD}_{5}$ & $\left(\mathrm{mg} \mathrm{L}^{-1}\right)$ & 1300 & $51-950$ \\
\hline $\mathrm{COD}$ & $\left(\mathrm{mg} \mathrm{L}^{-1}\right)$ & 1300 & $2150-3280$ \\
\hline Conductivity & $\left(\mathrm{mS} \mathrm{cm}^{-1}\right)$ & 5.8 & $7.5-7.7$ \\
\hline Nitrites/nitrates & $\left(\mathrm{mg} \mathrm{NO}_{3}-\mathrm{N} \mathrm{L}^{-1}\right)$ & 0 & $0.2-3.5$ \\
\hline pH & - & 7.75 & $7.74-8.09$ \\
\hline Total dissolved solids & $\left(\mathrm{mg} \mathrm{L}^{-1}\right)$ & 4310 & $4451-5057$ \\
\hline Total nitrogen & $\left(\mathrm{mg} \mathrm{N} \mathrm{L}^{-1}\right)$ & 200 & $421-447$ \\
\hline Total phosphorus & $\left(\mathrm{mg} \mathrm{P} \mathrm{L}^{-1}\right)$ & 8.0 & $13.7-15.2$ \\
\hline Total solids & $\left(\mathrm{mg} \mathrm{L}^{-1}\right)$ & 4310 & $4680-5264$ \\
\hline
\end{tabular}

\subsection{Analytical methods}

\subsubsection{Microbial community analysis}

\section{Genomic DNA extraction}

Genomic DNA was extracted from $10 \mathrm{ml}$ of each sample using a DNeasy Powersoil kit following the manufacturer's protocole (Quiagen). The final elution volume was $100 \mu \mathrm{l}$, and the 
concentration was determined with the Quant-it Picogreen kit (Thermofisher) and the NanoDrop 330 Fluorospectrometer (thermofisher).

\section{Illumina MiSeq}

The first PCR amplifications were performed with the primer Bakt_341F ( $5^{\prime}$ CCTACGGGNGGCWGCAG-3') and the primer Bakt_805R (5'-GACTACHVGGGTATCTAATCC-3'), designed by Herlemann et al. (2011) (Herlemann et al. 2011). Common sequence 1 (CS1) (5'ACACTGACGACATGGTTCTACA-3') and common sequence 2 (CS2) (5'TACGGTAGCAGAGACTTGGTCT-3') universal primer sequences, required for Illumina MiSeq amplicon tagging and indexing, were added to the $5^{\prime}$ ends of forward and reverse primers, respectively. Reaction conditions were $98^{\circ} \mathrm{C}$ for three minutes, followed by 30 cycles of $98^{\circ} \mathrm{C}$ for 10 seconds, $62^{\circ} \mathrm{C}$ for 20 seconds and $72^{\circ} \mathrm{C}$ for 30 seconds. Then a final elongation step of $72^{\circ} \mathrm{C}$ for 2 minutes was conducted. The first PCR products were used as templates for the second PCR. The second PCR conducted in order to add adapters and tags, as well as the amplified sequences purification were made by Génome Québec inc.

\section{Statistical analysis}

Bacterial population analysis results were interpreted using MicrobiomeAnalyst software (Dhariwal et al. 2017). The Marker Data Profiling module was used to compare the bacterial population in the different samples. A principal component analysis (PCOA) was also performed through MicrobiomeAnalyst in order to link the results of the microbial community analysis (richness and abundance of the OTUs) with the sMBR's operational parameters (HRT and SRT).

\subsubsection{Physico-chemical parameters analysis}

Water samples (feed and permeate) were analyzed for $\mathrm{pH}$ (Mettler Toledo SevenEasy), electrical conductivity (Mettler Toledo SevenCompact Conductivity), alkalinity (bromocresol green titration), solid content (total, dissolved, and volatile) (EPA Method 160.2), chemical oxygen demand (CEAEQ MA. 315 - DCO 1.1, Potassium dichromate), biological oxygen demand (5 days)(CEAEQ MA. 315 - DBO 1.1,), dissolved ammoniacal nitrogen (QuickChem Method 10-10706-2-O, salicylate - nitroprusside colorimetric method), dissolved nitrites/nitrates (QuickChem Method 10-107-04-2-B), total nitrogen (Shimadzu VCPH), and total phosphorus (Varian Vista AX ICP-AES). Total phosphorus content was determined after preliminary sample digestion (15\% trace metals grade $\mathrm{HNO} 3$ and $5 \% \mathrm{H} 2 \mathrm{O} 2$ at $95^{\circ} \mathrm{C}$ for 2 hours). Mixed liquor samples were analyzed for solid content (total, dissolved, and volatile) (EPA Method 160.2).

\section{Results and discussion}

\subsection{Acclimation from synthetic to real leachate}

The microbial community's diversity was compared between the mixed liquor when fed with synthetic leachate and when fed with real leachate. The alpha-diversity (Shannon) analyses, as well as the rarefaction curve, are presented in Figure $4 \mathrm{a}$ and Figure $4 \mathrm{~b}$. Due to the high species richness of two samples (>1000 OTUs), the Shannon alpha-diversity index was considered the most accurate method for sample comparison, since it takes both the number of different OTUs as well as their abundance into account. 


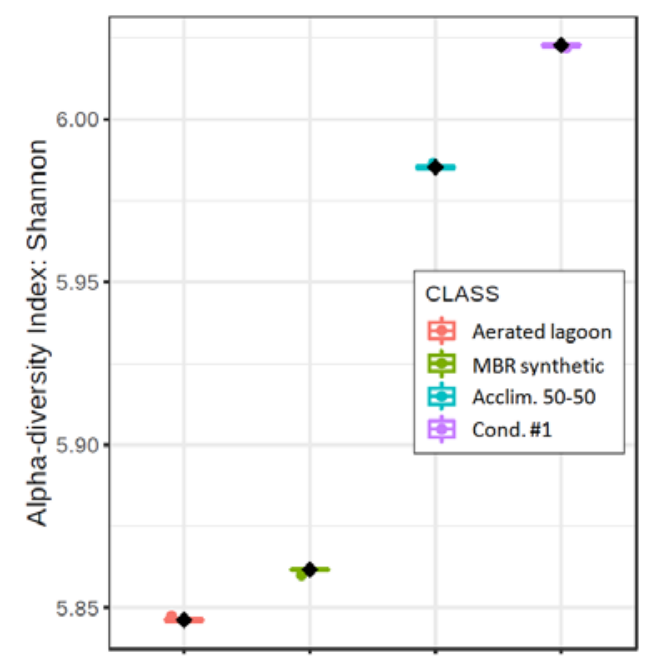

(a)

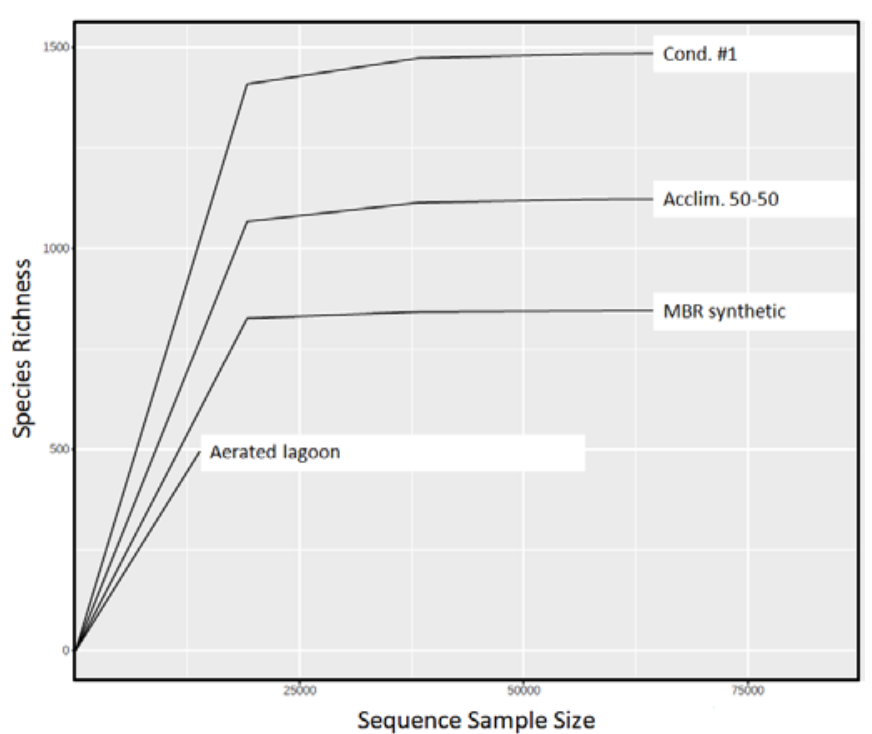

(b)

Figure 4 Alpha-diversity (Shannon) and rarefaction curves of sludge samples taken during acclimation

First, the aerated lagoon from which the mixed liquor samples were taken to inoculate the MBR showed the lowest Shannon $\alpha$-diversity index, with a value of 5.84 . This low diversity is explained by the low OTU count. According to the species richness analysis (Fig. 4b), only 14175 read counts were reported, compared to a read count of over 65000 for the other samples. This low read count was caused by both the high concentrations of inhibitory factors in the sample, such as humic- and fulvic-like substances, and by the sample's large fraction of inorganic suspended solids, due to it having been taken from the bottom of the lagoon. Furthermore, the species richness curve did not reach a plateau, which indicates that the total species richness of the sample might be higher than what is reported in this study.

Then, the Shannon $\alpha$-diversity analysis conducted on the MBR's mixed liquor showed an increasing diversity of the microbial community in the MBR mixed liquor as the synthetic leachate $(\alpha$-diversity $=5.87$ ) was replaced with real leachate originating from wastes ( $\alpha$-diversity $=6.05$ ). According to the species richness analysis, the number of different OTUs in the MBR's mixed liquor microbial community increased by more than $80 \%$ (from 840 to 1490 OTUs) after the complete replacement of the synthetic leachate with real leachate. The increased number of OTUs is the result of a combination of two factors: 1 ) the higher variety of substrate which can sustain a population with great substrate metabolism diversity, and 2) the real wastewater that can host low abundance microorganisms that act as a microorganisms seeder pool for the MBR's mixed liquor (Wittebolle et al. 2008).

In terms of substrate variety, the primary substrates of the synthetic leachate were limited in comparison to the real leachate. Synthetic leachate only contained acetate, propionate, and ammoniacal nitrogen. Thus, when the reactor was fed with synthetic leachate, the MBR's mixed liquor microbial population was dominated by microorganisms having a high metabolic activity for volatile fatty acids and ammoniacal nitrogen. Fig. 5 compares the microbial population structure at the genus taxonomic level of the MBR's mixed liquor samples (synthetic and real leachate). As seen in Fig. 5, the dominant OTU genera in the mixed liquor fed with synthetic leachate were: Comamonas $(25.9 \%)>$ Pseudoxanthomonas $(6.3 \%)>\operatorname{Subsaxibacter}(3.2 \%)>$ 
Trupera (3.2\%) > Nitrosomonas (3.0\%). The four dominant genera, which account for $38.6 \%$ of the total bacterial population, are aerobic chemo-organotrophs, and had been previously isolated from wastewater treatement sludge samples (Finkmann et al. 2000, Willems and De Vos 2006). In the mixed liquor fed with real leachates, the only dominant OTU genera (>3\%) were Comamonas $(41.6 \%)$ and Subsaxibacter (3.1\%), indicating that the variety of substrate contained in the wastewater allowed for the growth of a more diversified bacterial population with more substrate specific low abundance genera. Also, a previous study conducted on leachate originating from the same co-composting facility as those in this study found that most of the biodegradable organic carbon was present in the form of VFAs such as acetic, propionic, and butyric acids (Roy et al. 2019). The high proportion of heteretrophic bacteria Comamonas and Subsaxibacter in both MBR's mixed liquor is therefore strong evidence for the significant role that these two genera play in the degradation of volatile fatty acids (VFAs) in wastewater treatment systems.

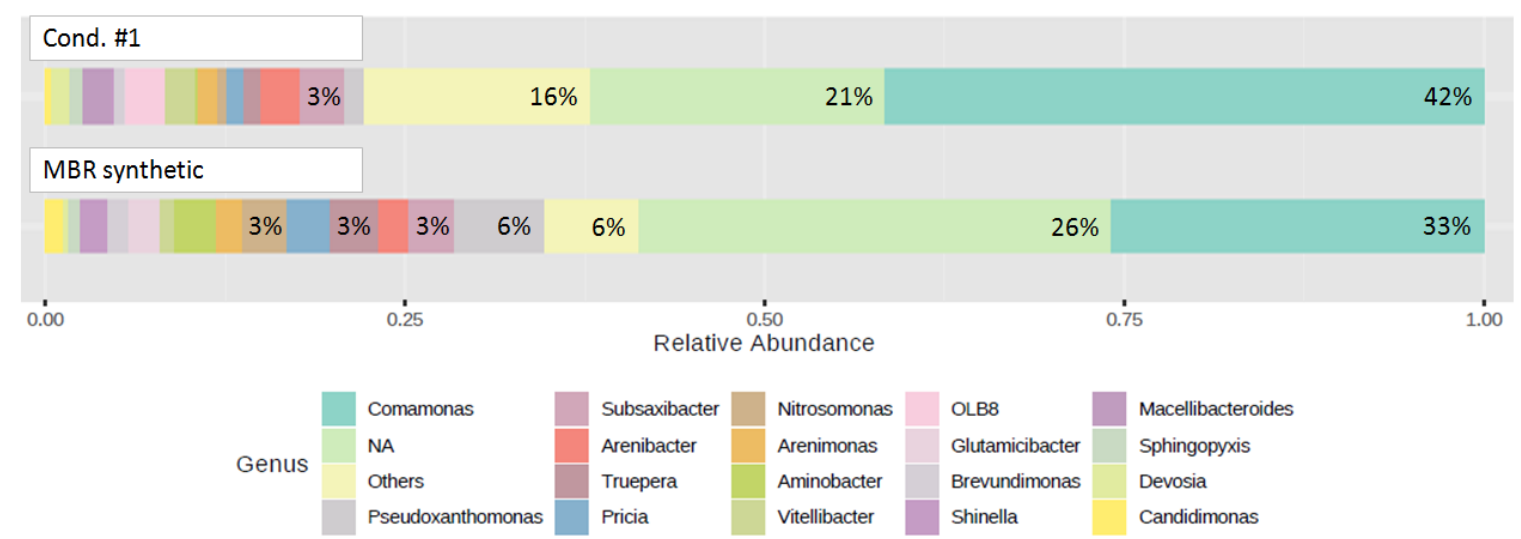

Figure 5 Microbial population structure in mixed liquor samples from the MBR fed with synthetic leachate (MBR synthetic) and real leachate (Cond. \#1)

Fig. 5 also highlights the fact that almost all OTUs making up more than $1 \%$ of the bacterial population are the same in both mixed liquors, with the exception of three OTUs: Aminobacter, Glutamicibacter, and OLB8. However, the proportion of OTUs with less than 800 sequence counts (less than $1 \%$ of the total bacterial population), identified as "Others" in Fig.5, increased from $6 \%$ to $16 \%$ when the synthetic leachate was replaced with real leachate. This $10 \%$ difference corresponds to 650 different OTUs that were not initially present in the mixed liquor before the replacement of the synthetic leachate with real leachate. Thus, the real wastewater acts as a seeder pool of microorganisms that might not significantly contribute to the metabolic function of the community, yet increases the population's diversity as well as the stability of the treatment system (Ma et al. 2013).

\subsection{Effect of the SRT and HRT on MBR's microbial community}

\section{structure}

The species richness analysis (Fig. 6a) conducted on the mixed liquor samples taken at each operating condition (See Table 2) showed that the bacterial population diversity increased at lower SRT. The average of the different genera counts were 2406 with a SRT of 30 days and HRTs of 36, 24 and $12 \mathrm{hrs}$, and 1893 with a SRT of 45 days and HRTs of $24 \mathrm{hrs}$ and $12 \mathrm{hrs}$. These results are in accordance with those from previous studies (Hu et al. 2012, Silva et al. 2010). Hu et al. (2012) found that the Simpson's diversity index and evenness index were lower in MBRs 
when compared to other wastewater treatment technologies (oxidation ditch systems and $\mathrm{A} / \mathrm{A} / \mathrm{O}(\mathrm{A} / \mathrm{O}$ ) systems) due to the difference in SRT and F/M (Hu et al. 2012). High SRTs provide more time for substrate-specific bacteria to adapt to a leachate's pollutants, so it stands to reason that the bacteria with greater adaptation ability would be enriched (Vuono et al. 2016). In addition, lower F/M at high SRTs increase the competition for substrate and nutrients, favoring the selection of acclimatized bacteria. Thus, increasing the SRT in the MBR significantly reduces the microbial community diversity.

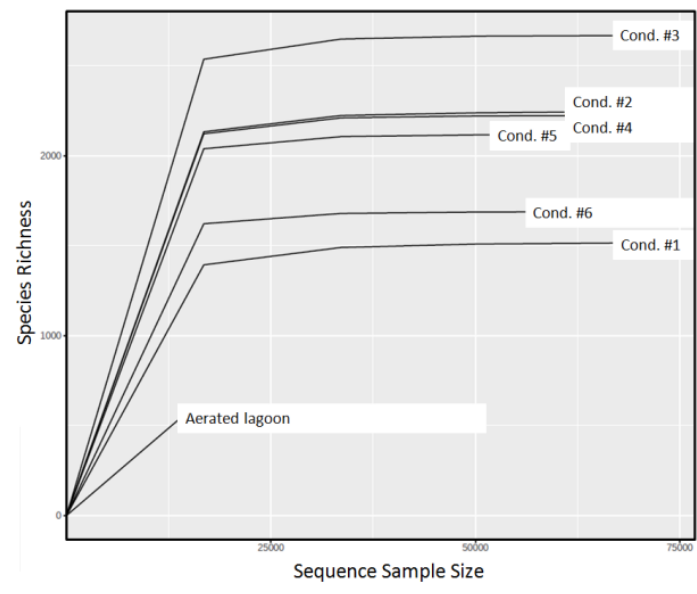

(a)

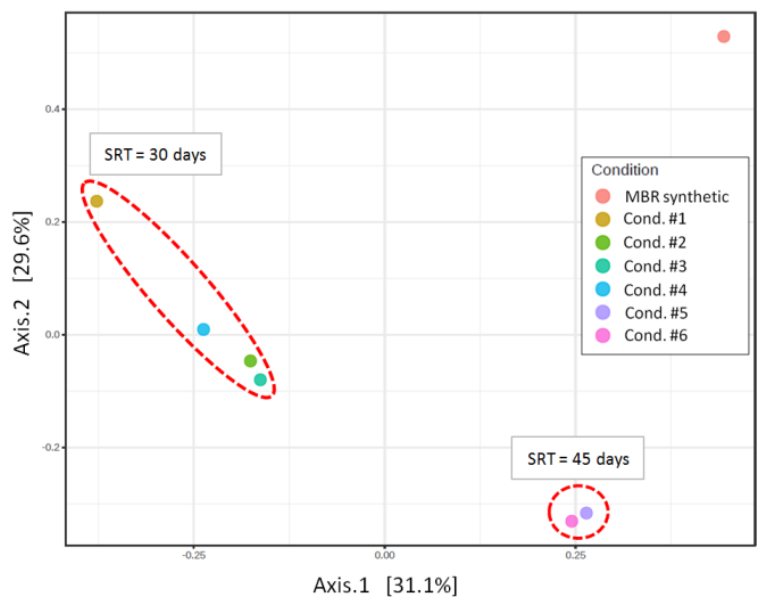

(b)

Figure 6 a) Species richness analysis and b) Principal component analysis of the MBR's mixed liquor samples taken at operating conditions \#1 to \#6

The principal component analysis (PCOA) linking the results of the microbial community analysis (richness and abundance of the OTUs) to the operational parameters (HRT and SRT) of the MBR is presented in Fig. 6b. Each dot on the graph represents a mixed liquor sample taken and its OTU profile. Theses dots are grouped into two distinct clusters; each cluster is associated with a specific SRT, which indicates a strong correlation between the mixed liquor SRT and the microbial population richness and abundance. These distinctions in microbial population are also in accordance with the results of Hu et al. (2012) (Hu et al. 2012). Furthermore, the distinct separation between the clusters is a strong indicator of a significant difference in the dominant OTUs' genera populating the mixed liquor at SRTs of 30 and 45 days. High SRTs provide the slow growing microorganisms with the opportunity to proliferate and to occupy a place in the microbial community, which is not possible at low SRT due to a constant dilution of their population (Ma et al. 2018).

The distance between the Cond. \#1 dot and the other dots in the same cluster of Fig. $6 \mathrm{~b}$ indicates that the HRT influences the microbial population due to the difference in $\mathrm{F} / \mathrm{M}$. Increasing the HRT reduces the F/M, which explains the lower species richness at Cond. \#1 (HRT = 48hrs) when compared to Cond. \#2, \#3, and \#4 (HRTs of 36, 24 and $12 \mathrm{hrs,} \mathrm{respectively).}$ However, the proximity of the dots from samples taken at HRTs from 36 to $12 \mathrm{hrs}$ at both SRTs (30 and 45 days) indicates no significant impact on the microbial population (diversity and richness) in that specific range of HRTs.

\subsubsection{Effect of the SRT and HRT at the phylum level}


The bacterias' phyla distribution in the microbial population of the mixed liquor samples are presented in Fig. 7a. In all the MBR's mixed liquor samples, the vast majority of the bacteria belonged to two phyla: Proteobacteria (57 to $71 \%$ ) and Bacteriodetes (10 to 33\%). These results are in accordance with those previously reported by Xue et al. (2015) in a study on MBR treating landfill leachates (Xue et al. 2015). Similarly, Hu et al (2012) reported that both Proteobacteria and Bacteriodetes can be found as the dominant phyla in MBRs treating municipal wastewaters (Hu et al. 2012). Furthermore, these phyla were previously affiliated with landfill leachates. Köchling et al. (2015) found that the Firmicutes, Proteobacteria, and Bacteroidetes phyla are the most abundant taxonomic groups found in the complex microbial communities harbored by landfill leachates (Köchling et al. 2015).

The subdominant phyla populating the MBR's mixed liquor when operated at a SRT of 30 days were mainly composed of Plantomycetes, Actinobacteria, and Acidobacteria. The phylum Deinococcus-Thermus appeared in high relative abundance (6\%) at Cond. \#3 (SRT = 30 days, HRT $=24 \mathrm{~h}$ ). This phylum includes several thermophiles. Their presence in the MBR is linked to the thermophilic composting stage from which the leachate orginates. Deinococcus-Thermus' high resistance to environmental hazards may help it adapt to highly contaminated leachates (Griffiths and Gupta 2007).

When the SRT is increased from 30 to 45 days, the subdominant phylum Actinobacteria is replaced by Chloroflexi. Commonly found in aquatic environments, Chloroflexi is suspected to play a role in denitrification, but it does not possess the enzymes responsible for the production of molecular nitrogen (Mehrshad et al. 2018). Zhang et al. (2015) also suggested that Chloroflexi could act as the backbone for microbial flocs (Zhang et al. 2015). Actinobacteria, for its part, has been associated with sludge reduction properties in aerated lagoons with high SRT (Low F/M) (Chen et al. 2017). Therefore, increasing the SRT could provide better sludge settling properties due to a better microbial floc structure and less saprophytic activity by Actinobacteria.

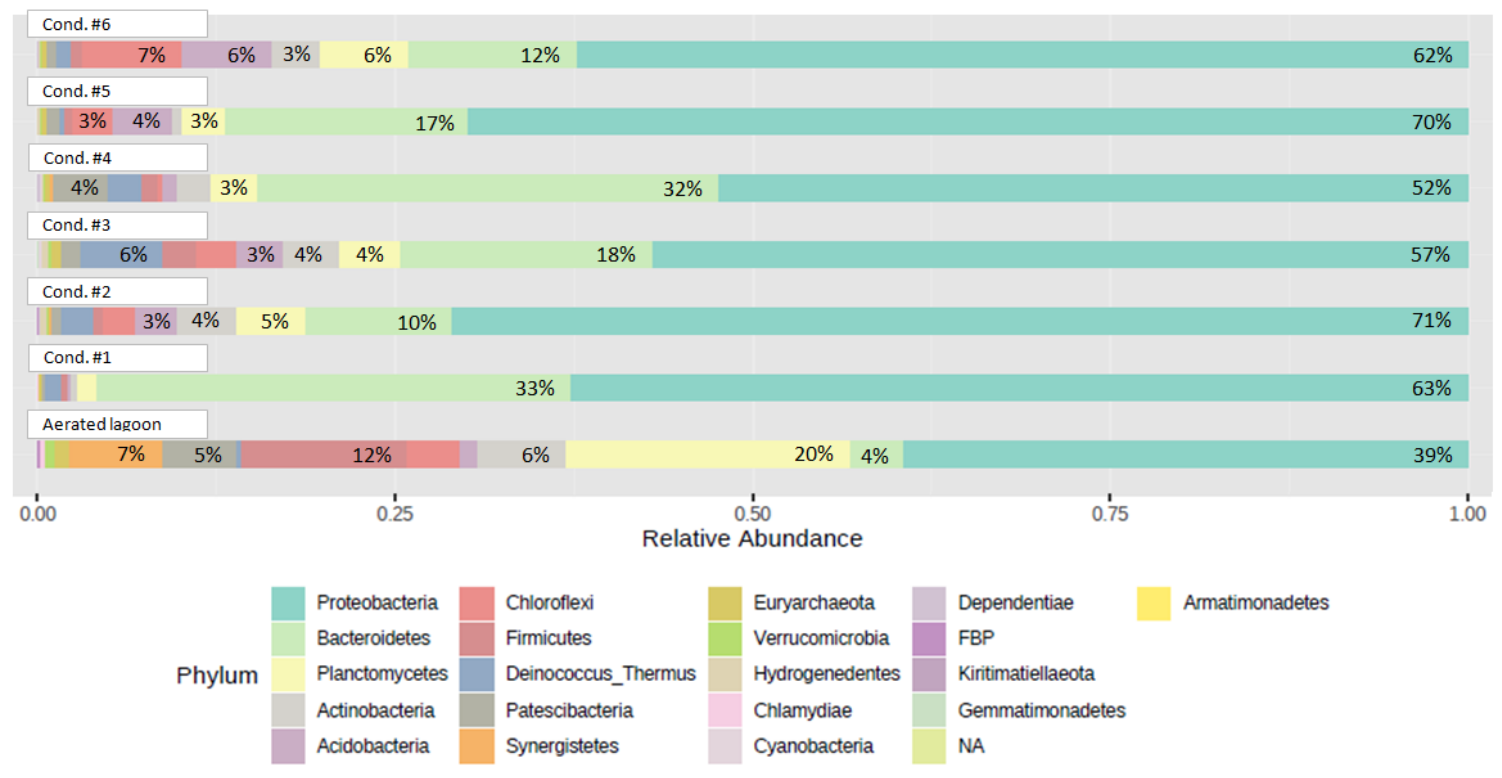

(a) 


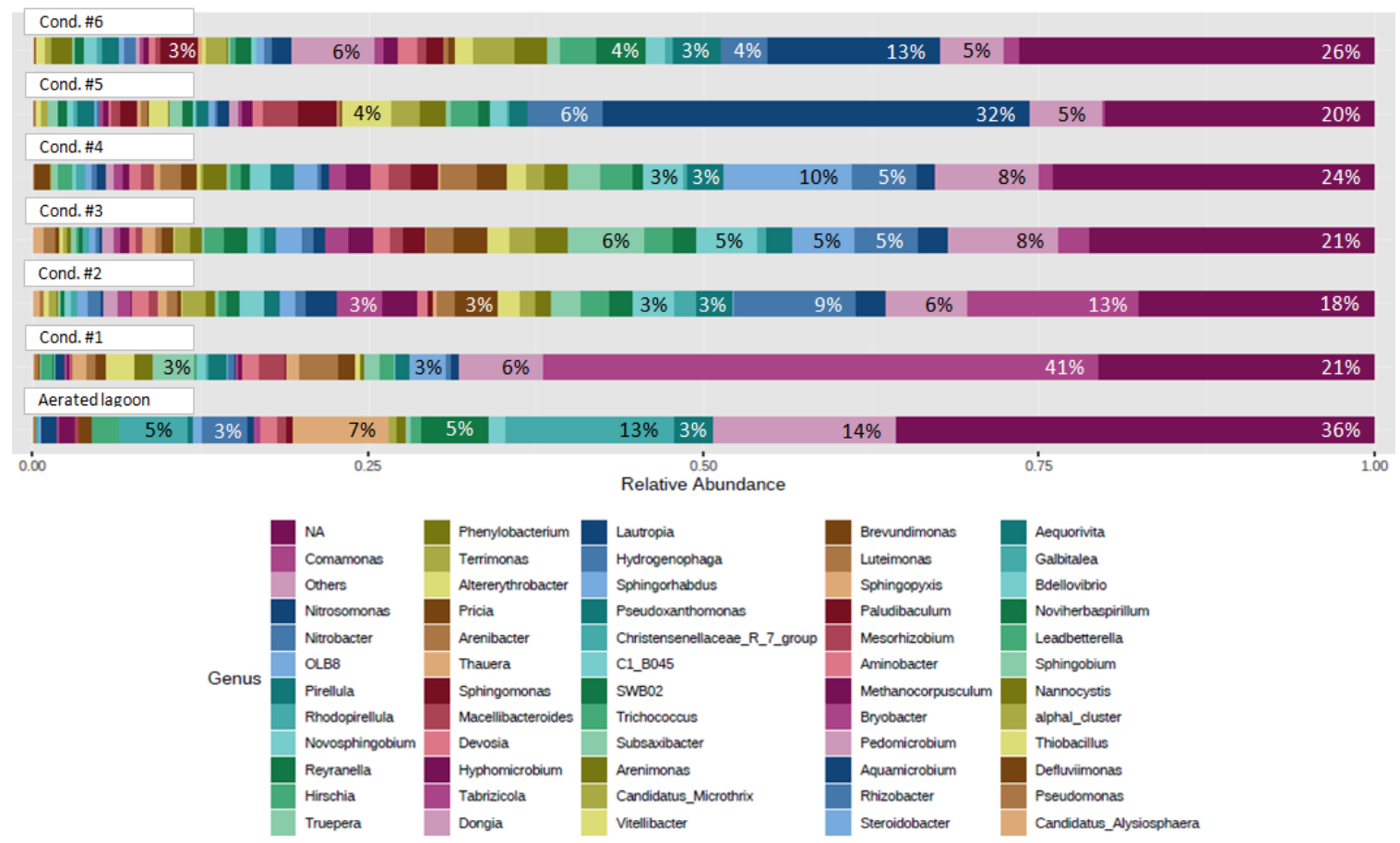

(b) level

Figure 7 Microbial population distribution in mixed liquor samples at a) the phylum level and b) the genus

\subsubsection{Effect of the SRT and HRT at the genus level}

The distribution of bacteria genera in the microbial population of the mixed liquor samples is presented in Fig. 7b. The dominant genus in the mixed liquor samples taken from the MBR operated at a SRT of 30 days varies significantly between the different HRTs tested. Comamonas dominate the microbial population at a HRT of $48 \mathrm{hrs}$ (relative abundance of $41 \%$ ) and are gradually replaced by subdominant groups when the HRT is reduced to 36,24 , and $12 \mathrm{hrs}$ (relative abundances of 13,2 , and $1 \%$, respectively). Comamonas are known for their ability to break down a wide variety of complex organic compounds and were previously isolated from denitrifying activated sludge (Gumaelius et al. 2001). At high HRT, easily biodegradable organic substrates from leachates are quickly consumed, leaving only complex molecules, such as humic- and fulvic-like acids, for heterotrophic microorganisms to feed on. In such low F/M conditions, Comamonas are enriched due to their capacity to degrade aromatic compounds and higher dicarboxylic acids (Willems and De Vos 2006). Therefore, Comamonas could play a significant role in the degradation of recalcitrant organic contaminants in reactors operated at high HRTs. At lower HRTs (higher F/M), Comamonas are replaced by a few subdominant groups (relative abundance $>3 \%$ ), including Nitrobacter, OLB8, Pirellula, Novosphingobium, Truepera, and Arenibacter. Nitrobacter is well known for its role in the nitrification process by oxidizing nitrite into nitrate. OLB8, for its part, has been isolated from a partial-nitritation anammox (PNA) reactor at Olburgen (Netherlands). OLB8 genus expresses the NOS gene, which means it has the capacity to convert nitrates to dinitrogen $\left(N_{2}\right)$ (Speth et al. 2016). According to the results presented in Fig. 7b, Nitrobacter and OLB8 rank higher in the abundance curve at high $\mathrm{F} / \mathrm{M}$ ratio. The genus Truepera is attached to the phylum Deinococcus-Thermus, and has been reported to exist in activated sludge systems (El-Fadel et al. 2018) and some extreme 
environments (Liu et al. 2017). Both Novosphingobium and Arenibacter are ubiquitous marine microorganisms capable of degrading high-molecular-mass polycyclic aromatic molecules such as polycyclic aromatic hydrocarbons (PAHs) (Gutierrez et al. 2014, Sohn et al. 2004). Their presence at higher F/M indicates that these genera (Truepera, Novosphingobium, and Arenibacter) become of importance for COD removal when a high quantity of aromatic organic carbon is fed to the reactor. Results from Cond. \#1 to Cond. \#4 indicate that increasing the F/M ratio by reducing the HRT breaks down the dominant genus into several subdominant genera, and increases the species richness of the mixed liquor. Thus, considering that wastewater biotreatment systems are more stable when the microbial diversity is high, MBRs should be operated at low HRT when treating variable composition leachates unless complex molecules needing treatment are present (Ma et al. 2013, Rowan et al. 2003).

From Cond. \#4 to Cond. \#5, the MBR's SRT is increased from 30 to 45 days. The first major change observed in the microbial community is the relative abundance of Nitrosomonas, which increases from less than $2 \%$ (Cond. \#4) to $32 \%$ (Cond. \#5) and becomes the dominant genus in the mixed liquor. These results indicate that 30 days of SRT is the near minimum value at which Nitrosomonas can grow faster than they are wasted and develop into a stable population that can outcompete the heterotrophic OTUs for oxygen and nutrients. Similarly, El-Fadel et al. (2018) reported that ammonia and nitrite oxidizing bacteria were not detected in their leachate treating MBR at SRTs ranging from 5 to 20 days, suggesting that 20 days of SRT is not sufficient for nitrifiers to be enriched (El-Fadel et al. 2018). From Cond. \#5 to Cond. \#6, the HRT is decreased from $24 \mathrm{hrs}$ to $12 \mathrm{~h}$, resulting in a Nitrosomonas relative abundance reduction from $32 \%$ to $13 \%$. According to the PCoA in Fig $6 \mathrm{~b}$, the microbial population structure remained highly similar between the two HRTs. However, increasing the F/M by reducing the HRT from $24 \mathrm{hrs}$ to $12 \mathrm{hrs}$ lessens the selectivity pressure and leads to the proliferation of subdominant genera, as observed from Cond. \#1 to Cond. \#4.

In terms of population abundance, Nitrosomonas is replaced by five main subdominant genera: Dongia (6\%), Reyranella (4\%), Pirellula (3\%), Paludibaculum (3\%), and Phenylobacterium (3\%). Pirellula is the only genus that is also subdominant (>3\%) at a SRT of 30 days at similar HRTs. Pirellula were reported to be the most abundant planctomycete in municipal wastewater treatment plants (Chouari et al. 2003). According to Glöckner et al. (2003), the Pirellula genus gains its energy from mono- or disaccharides derived from the cleavage of sulfated polymers. Pirellula can grow under limited-nitrogen conditions and can outlast periods of nutrient depletion thanks to carbon starvation genes (Glöckner et al. 2003). Dongia was previously isolated from a sequencing batch reactor and has the ability to reduce nitrate to nitrite (Liu et al. 2010). Reyranella, Paludibacterium, and Phenylobacterium are all heterotrophic bacteria that are ubiquitous in soil and marine environments. Paludibacterium was previously identified as the dominant genus in a culture grown in a selective media containing only PAH as carbon source, but was found to have no capacity to degrade PAH (Huang et al. 2019). Thus, Paludibacterium might play a role in the degradation of cellular components and in the reduction of sludge production. Phenylobacterium is capable of degrading heterocyclic and aromatic compounds, including xenobiotic molecules such as herbicides (Eberspächer and Lingens 2006). Similarly to Truepera, Novosphingobium, and Arenibacter that were subdominant at a SRT of 30 days, Phenylobacterium seems to play a leading role in the degradation of recalcitrant organic carbon at higher F/M. Results from Cond. \#5 and \#6 confirm that increasing the F/M ratio by reducing the HRT breaks down the dominant genus into several subdominant genera. Furthermore, changing the SRT significantly modifies the microbial structure by selecting microorganisms with different growth rates. 


\subsection{Leachate treatment performances}

\subsubsection{Organic contamination $\left(B O D_{5}, C O D\right)$}

The MBR's feed and permeate COD concentration, as well as the feed's $\mathrm{BOD}_{5} / \mathrm{COD}$ for each tested condition, is presented in Fig. 8a. The F/M expressed in COD consumption rate per mass of MLVSS is presented in Fig. $8 \mathrm{~b}$. In Fig. $8 \mathrm{a}$, both the COD and the $\mathrm{BOD}_{5} / \mathrm{COD}$ decreased between Cond. \#1 and Cond. \#6 despite the preservation efforts to maintain the leachates' composition constant. However, permeates' COD concentrations remained constant at $1675 \pm 74 \mathrm{mg} \mathrm{L}^{-1}$ in all conditions, indicating that the recalcitrant fraction of the organic contamination was unaffected by the operating condition (SRTs between 30 and 45 days, and HRTs between 12 and $48 \mathrm{hrs}$ ) and the mixed liquor's microbial population structure.

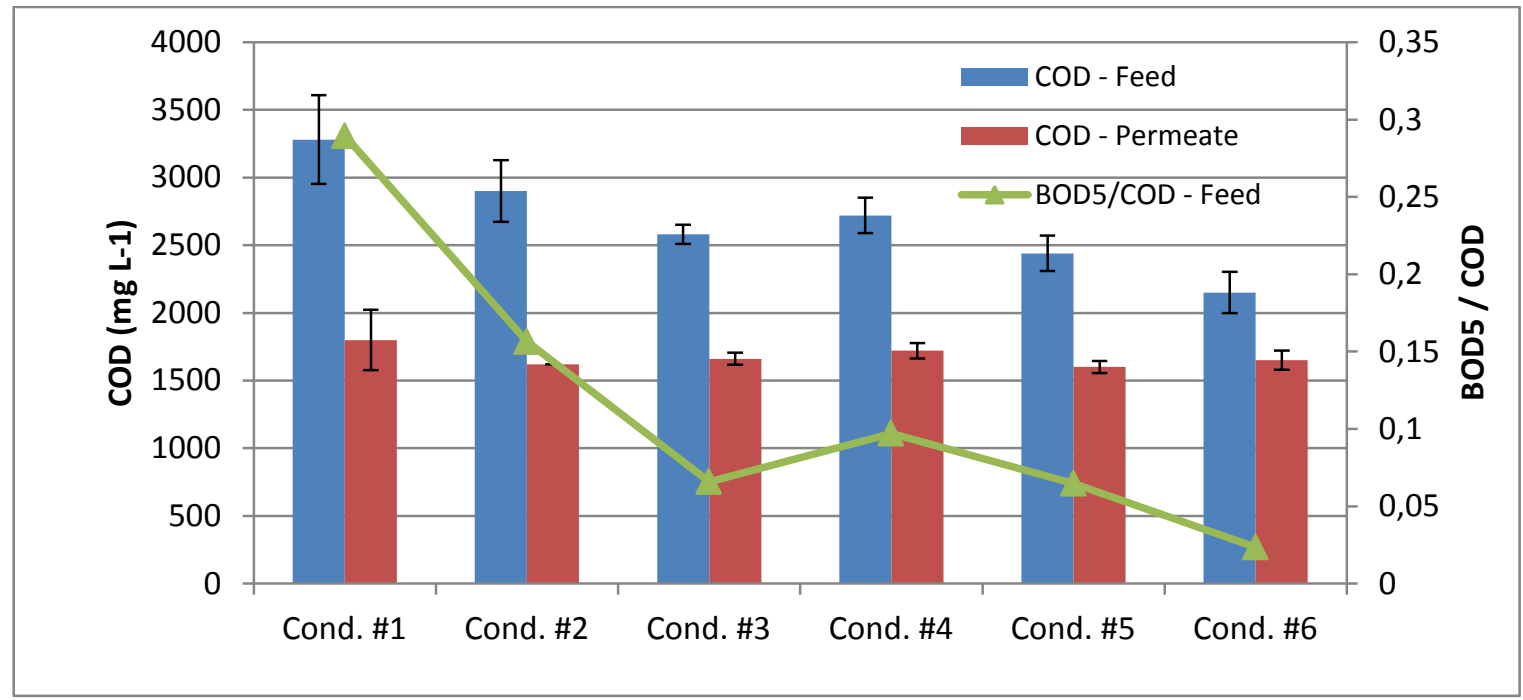

(a)

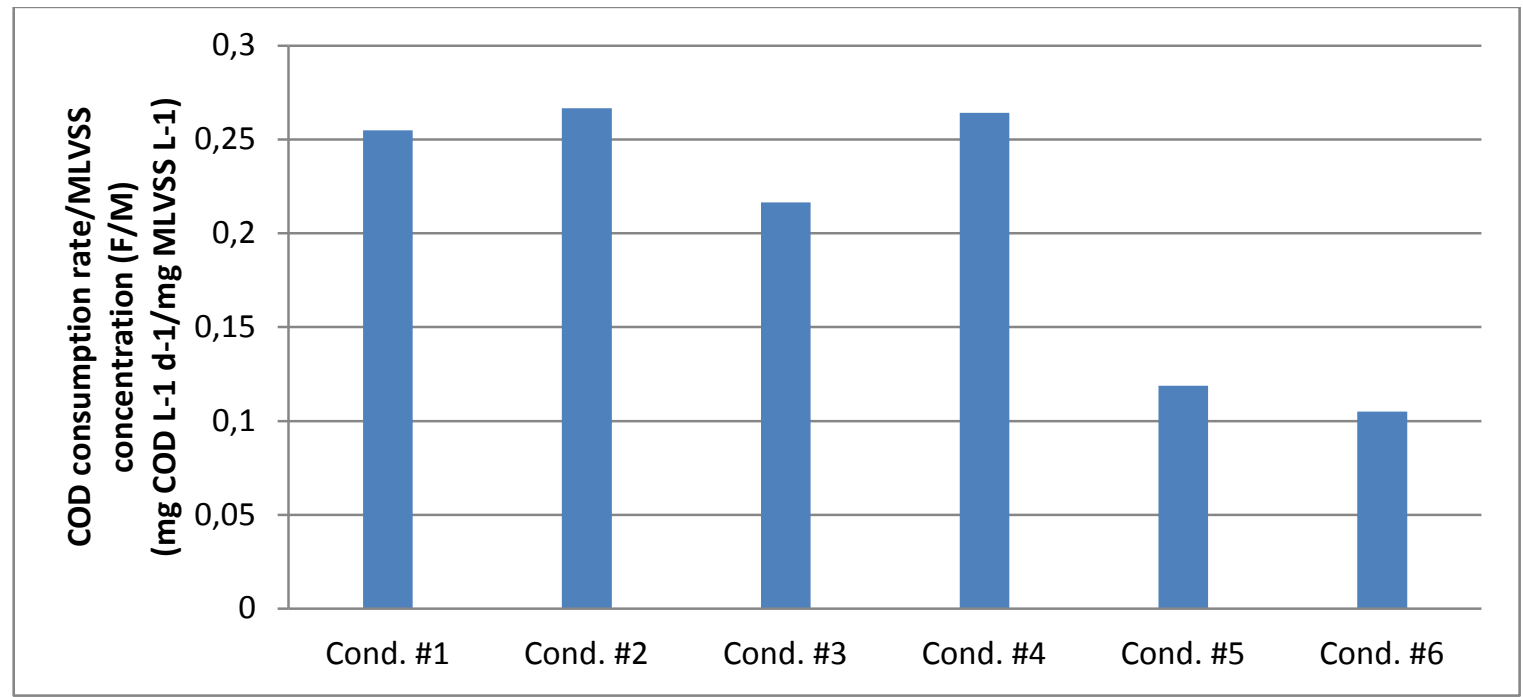

(b)

Figure 8 a) MBR's feed and permeate COD concentration and b) F/M expressed in COD consumption rate per mass of MLVSS for each tested condition 
In Fig. $8 b$, at steady-state condition, the $F / M$ is shown to remain quite constant at $0,25 \pm 0,02$ and $0,11 \pm 0,01 \mathrm{mg} \mathrm{COD} \mathrm{L}^{-1} \mathrm{~d}^{-1} / \mathrm{mg} \mathrm{MLVSS} \mathrm{L}^{-1}$ at SRTs of 30 and 45 days, respectively. This result indicates that no matter which genera are dominant, the microbial population concentration in the MBR adjusts itself proportionally to the amount of substrate provided by the feed and the $\mathrm{F} / \mathrm{M}$ value is dependent on the SRT only. According to the results presented in Fig. $7 \mathrm{~b}$ and Fig. $8 \mathrm{~b}$, the low F/M obtained by increasing the SRT results in the selection of two dominant types of bacteria. The first type includes genera with low growth rates that feed on non-limiting substrates or substrates with few competitors. For example, changing the SRT from 30 to 45 days increased the Nitrosomonas' relative abundance from $2 \%$ to $32 \%$. The second type includes genera with metabolisms that are highly specific to the available substrates and that can outcompete the other genus by using the substrate more efficiently. The low F/M value measured at a SRT of 45 days indicates that microorganisms use the available substrate more efficiently at a SRT of 45 days than at a SRT of 30 days, due to the fact that more microorganisms can thrive with less substrate. Based on the previous hypothesis, heterotrophic genera Reyranella, Paludibacterium, and Phenylobacterium, which are subdominant groups at a SRT of 45 days, might be more efficient in metabolizing leachate's COD than heterotrophic genera Novosphingobium, Truepera, and Arenibacter, which are subdominant at a SRT of 30 days.

\subsubsection{Ammoniacal nitrogen}

Nitrogen from composting leachate is found as: 1) proteinaceous compounds, 2) amines integrated into fulvic- and humic-like substances, and 3) ammonium salts (Green and Popa 2012, He et al. 2015). In this study, the leachate treated has an average ammonium concentration of

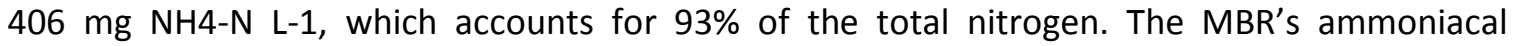
nitrogen load rates and removal rates, as well as the associated genera's relative abundances, are presented in Table 4. At a SRT of 30 days, the ammonium concentration in the permeate remains in the range of 0.4 to $2.8 \mathrm{mg} \mathrm{NH}_{4}-\mathrm{N} \mathrm{L}^{-1}$ for NLRs ranging from 191 to $742 \mathrm{mg} \mathrm{NH}_{4}-\mathrm{N} \mathrm{L}^{-1} \mathrm{~d}^{-}$ ${ }^{1}$, corresponding to removal percentages of $>99.3 \%$. Similarly, at a SRT of 45 days, ammonium concentrations of 0.6 and $2.7 \mathrm{mg} \mathrm{NH}_{4}-\mathrm{N} \mathrm{L}^{-1}$ were obtained in the permeate for NLRs ranging from 382 and $741 \mathrm{NH}_{4}-\mathrm{N} \mathrm{L}^{-1} \mathrm{~d}^{-1}$, corresponding to removal percentages of $>99.3 \%$. During the nitrification process, ammoniacal nitrogen is first oxidized to nitrite by Nitrosomonas and/or Nitrosospira through the involvement of ammonia monooxygenase (amoA) (Remmas et al. 2016). Then, nitrite oxidizers of the genera Nitrobacter and/or Nitrospira catalyse the oxidation of nitrite to nitrate through the involvement of nitrite oxydoreductase (nxrA) (Carrera et al. 2004). Nitrosomonas are the predominant ammonia oxidizing bacteria (AOB) in all mixed liquor samples, which is in accordance with previous studies conducted on landfill leachates treatment (Xie et al. 2013). According to Terada et al. (2013), high $\mathrm{NH}_{4}{ }^{+}$concentration favor the growth of Nitrosomonas because its $\mathrm{NH}_{4}{ }^{+}$half saturation coefficient is higher than for Nitrosospira (Terada et al. 2013). At a SRT of 30 days (Cond. \#1 to \#4), Nitrosomonas relative abundance is negatively impacted when the HRT is reduced from $36 \mathrm{hrs}$ to $12 \mathrm{hrs}$ (Cond. \#2 to Cond. \#4), despite an increased NLR. Conversely, Nitrospira relative abundances linearly increase from 0.07 to $0.83 \%$ as the NLR increases from 191 to $742 \mathrm{mg} \mathrm{NH}_{4}-\mathrm{N} \mathrm{L}^{-1} \mathrm{~d}^{-1}$ from Cond. \#1 to \#4, respectively. The same trend is observed at a SRT of 45 days. Nitrosomonas' relative abundance decreases from 32 to $13 \%$ while Nitrospira's relative abundance increases from 0.02 to $0.09 \%$ when the HRT is reduced from $24 \mathrm{hrs}$ to $12 \mathrm{hrs}$. These results are in accordance with those of Remmas et al. (2012), which linked the AOB population structure to the increasing OLR at low HRTs. Their 
study showed that Nitrosomonas are highly affected by the organic load increase, while Nitrosospira strains are able to tolerate such increase, further explaining the trends observed in this study (Remmas et al. 2016). However, despite such variations in amoA gene expressing bacteria abundance, the ammonia removal rates remain unchanged in the NLR range of 191 to $742 \mathrm{mg} \mathrm{NH}_{4}-\mathrm{N} \mathrm{L}^{-1} \mathrm{~d}^{-1}$.

The absence of Nitrospira in the mixed liquor samples indicate that nitritation in the studied MBR is entirely associated to Nitrobacter. The residual ammoniacal nitrogen concentration measured in the permeate exceeds the Nitrospira inhibition level of $0.1 \mathrm{mg} \mathrm{NH}_{4}-\mathrm{N} \mathrm{L}^{-1}$ proposed by Terada et al. (2013), which explains its absence (Terada et al. 2013). Therefore, Nitrobacter is the only nitrite oxidizing bacteria that can thrive in single stage bioreactors treating highstrength ammoniacal nitrogen wastewaters. Nitrobacter's relative abundance followed Nitrosomonas's trend, indicating that its growth can also be inhibited when the OLR increases.

Table 4 Ammoniacal nitrogen removal performances and associated genera relative abundances

\begin{tabular}{|c|c|c|c|c|c|c|c|c|}
\hline & \multicolumn{2}{|l|}{$\mathrm{NH}_{4}^{+}$removal } & \multicolumn{6}{|c|}{ Nitrificants and denitrificants abundances (\%) } \\
\hline & \multirow{2}{*}{$\begin{array}{l}\mathrm{NLR} \\
\left(\mathrm{mg} \mathrm{NH}_{4}-\mathrm{N} \mathrm{L}^{-1} \mathrm{~d}^{-1}\right)\end{array}$} & \multirow{2}{*}{\begin{tabular}{l|} 
Removal \\
$(\%)$
\end{tabular}} & \multicolumn{2}{|l|}{ amoA } & \multirow{2}{*}{$\begin{array}{l}\text { nxrA } \\
\text { Nitrobacter }\end{array}$} & \multicolumn{3}{|l|}{ nirS } \\
\hline & & & Nitrosomonas & Nitrosospira & & Comamonas & Arenimonas & Simplicispira \\
\hline Cond. \#1 & 191 & 99.3 & 0.64 & 0.07 & 0.37 & 32 & 1.4 & 0.41 \\
\hline Cond. \#2 & 269 & 99.8 & 2.3 & 0.21 & 9.0 & 13 & 0.63 & 0.20 \\
\hline Cond. \#3 & 397 & 99.9 & 2.1 & 0.50 & 4.8 & 2.1 & 1.1 & 0.27 \\
\hline Cond. \#4 & 742 & 99.8 & 1.4 & 0.83 & 4.8 & 1.0 & 1.7 & 0.04 \\
\hline Cond. \#5 & 382 & 99.9 & 32 & 0.02 & 5.6 & 0.23 & 1.3 & 0.69 \\
\hline Cond. \#6 & 741 & 99.3 & 13 & 0.09 & 3.5 & 1.0 & 0.07 & 0.12 \\
\hline
\end{tabular}

Finally, the OTUs' genera identified in the mixed liquor samples are compared to the list of nirS expressing OTUs isolated from an intermittently aerated and fed MBR treating landfill leachate by Remmas et al. (2016) (Remmas et al. 2016). Interestingly, while there is no denitrification activity observed during this experiment because of a high DO concentration maintained in the $\operatorname{sMBR}\left(>7 \mathrm{mg} \mathrm{L}^{-1}\right)$, bacteria expressing nirS gene are present in significant abundance. Those ranking the highest are Comaminas, Arenimonas, and Simpliscispira.

\section{Conclusion}

As a first step, this study assessed the evolution of the bacterial community structure and diversity in a MBR when the synthetic feed wastewater was replaced by real leachate originating from a co-composting facility. The mixed liquor species richness increased by more than $80 \%$ when the synthetic leachate was replaced by real leachates indicating that real wastewater host low abundance microorganisms that act as a microorganisms seeder pool for the MBR's mixed liquor.

Then, this study linked the bacterial community structure to the solid retention time (SRT) and the contaminant load rates (COD and $\mathrm{NH}_{4}{ }^{+}$). In this context, the sMBR was operated at SRTs of 30 and 45 days and HRTs of $12,24,36$, and 48 hours, using real leachate. Results showed that increasing the F/M by reducing the HRT (or the contaminant load rates) lessened the selectivity pressure, which allowed the proliferation of subdominant OTUs that were otherwise inhibited 
by highly adapted dominant OTUs. The breakdown of the dominant OTUs at low HRTs led to an increase in the mixed liquor's bacterial diversity. Furthermore, increasing the SRT resulted in a lower microbial diversity and in the selection of two dominant types of bacteria. The first type includes genera with low growth rate which feed on non-limiting substrates or substrates with few competitors. Thus, Nitrosomonas' relative abundance increased from $2 \%$ to $32 \%$ when the SRT was increased from 30 to 45 days. The second type includes genera with metabolisms that are highly specific to the available substrates and that can outcompete the other genera by using the substrate more efficiently. Consequently, the relative COD consumption rate decreased, and the sludge production increased.

The bacterial population evolution observed during this study suggests that the population diversity and structure can be modulated for the bioenhancement of contaminant specific catabolic activity. Therefore, most of the aquatic pollutant found in wastewaters could be biologically treated with the right combination of operating conditions, including the HRT and the SRT.

\section{Acknowledgements}

Support for this study was provided by the NSERC, under a cooperative agreement with the Institut national de la recherche scientifique (INRS), Englobe Corp., and Centre National en Électrochimie et en Technologies Environnementales (CNETE); and by a MITACS doctoral scholarship from MITACS and Englobe Corp. The author would also like to thank Nathalie Couët for copy editing. 


\section{References}

Renou, S., Givaudan, J.G., Poulain, S., Dirassouyan, F. and Moulin, P. (2008) Landfill leachate treatment: Review and opportunity. Journal of Hazardous Materials 150(3), 468-493.

Ahmed, F.N. and Lan, C.Q. (2012) Treatment of landfill leachate using membrane bioreactors: A review. Desalination 287, 41-54.

Ramakrishnan, A., Blaney, L., Kao, J., Tyagi, R.D., Zhang, T.C. and Surampalli, R.Y. (2015)

Emerging contaminants in landfill leachate and their sustainable management. Environmental Earth Sciences 73(3), 1357-1368.

Roy, D., Benkaraache, S., Azaïs, A., Drogui, P. and Tyagi, R.D. (2019) Leachate treatment: Assessment of the systemic changes in the composition and biodegradability of leachates originating in an open co-composting facility in Canada. Journal of Environmental Chemical Engineering 7(3), 103056.

El-Fadel, M., Sleem, F., Hashisho, J., Saikaly, P.E., Alameddine, I. and Ghanimeh, S. (2018) Impact of SRT on the performance of MBRs for the treatment of high strength landfill leachate. Waste Management 73, 165-180.

Roy, D., Azaïs, A., Benkaraache, S., Drogui, P. and Tyagi, R.D. (2018) Composting leachate: characterization, treatment, and future perspectives. Reviews in Environmental Science and Bio/Technology.

Ng, A.N. and Kim, A.S. (2007) A mini-review of modeling studies on membrane bioreactor (MBR) treatment for municipal wastewaters. Desalination 212(1-3), 261-281.

Hu, M., Wang, X., Wen, X. and Xia, Y. (2012) Microbial community structures in different wastewater treatment plants as revealed by 454 -pyrosequencing analysis. Bioresource Technology 117, 72-79.

Köchling, T., Sanz, J.L., Gavazza, S. and Florencio, L. (2015) Analysis of microbial community structure and composition in leachates from a young landfill by 454 pyrosequencing. Applied Microbiology and Biotechnology 99(13), 5657-5668.

Xue, Y., Zhao, H., Ge, L., Chen, Z., Dang, Y. and Sun, D. (2015) Comparison of the performance of waste leachate treatment in submerged and recirculated membrane bioreactors. International Biodeterioration \& Biodegradation 102, 73-80.

Gonzalez-Martinez, A., Sihvonen, M., Muñoz-Palazon, B., Rodriguez-Sanchez, A., Mikola, A. and Vahala, R. (2018) Microbial ecology of full-scale wastewater treatment systems in the Polar Arctic Circle: Archaea, Bacteria and Fungi. Scientific Reports 8(1), 2208.

Canziani, R., Emondi, V., Garavaglia, M., Malpei, F., Pasinetti, E. and Buttiglieri, G. (2006) Effect of oxygen concentration on biological nitrification and microbial kinetics in a cross-flow membrane bioreactor (MBR) and moving-bed biofilm reactor (MBBR) treating old landfill leachate. Journal of Membrane Science 286(1), 202-212.

Duan, L., Moreno-Andrade, I., Huang, C.-I., Xia, S. and Hermanowicz, S.W. (2009) Effects of short solids retention time on microbial community in a membrane bioreactor. Bioresource Technology 100(14), 3489-3496.

Herlemann, D.P., Labrenz, M., Jurgens, K., Bertilsson, S., Waniek, J.J. and Andersson, A.F. (2011) Transitions in bacterial communities along the $2000 \mathrm{~km}$ salinity gradient of the Baltic Sea. Isme $\mathrm{j}$ 5(10), 1571-1579.

Dhariwal, A., Chong, J., Habib, S., King, I.L., Agellon, L.B. and Xia, J. (2017) MicrobiomeAnalyst: a web-based tool for comprehensive statistical, visual and meta-analysis of microbiome data. Nucleic Acids Research 45(W1), W180-W188.

Wittebolle, L., Vervaeren, H., Verstraete, W. and Boon, N. (2008) Quantifying community dynamics of nitrifiers in functionally stable reactors. Appl. Environ. Microbiol. 74(1), 286-293. 
Finkmann, W., Altendorf, K., Stackebrandt, E. and Lipski, A. (2000) Characterization of N2Oproducing Xanthomonas-like isolates from biofilters as Stenotrophomonas nitritireducens sp. nov., Luteimonas mephitis gen. nov., sp. nov. and Pseudoxanthomonas broegbernensis gen. nov., sp. nov. Int J Syst Evol Microbiol 50 Pt 1, 273-282.

Willems, A. and De Vos, P. (2006) The Prokaryotes: Volume 5: Proteobacteria: Alpha and Beta Subclasses. Dworkin, M., Falkow, S., Rosenberg, E., Schleifer, K.-H. and Stackebrandt, E. (eds), pp. 723-736, Springer New York, New York, NY.

Ma, J., Wang, Z., Yang, Y., Mei, X. and Wu, Z. (2013) Correlating microbial community structure and composition with aeration intensity in submerged membrane bioreactors by 454 highthroughput pyrosequencing. Water Research 47(2), 859-869.

Silva, C.C., Jesus, E.C., Torres, A.P., Sousa, M.P., Santiago, V.M. and Oliveira, V.M. (2010) Investigation of bacterial diversity in membrane bioreactor and conventional activated sludge processes from petroleum refineries using phylogenetic and statistical approaches. Journal of microbiology and biotechnology.

Vuono, D.C., Regnery, J., Li, D., Jones, Z.L., Holloway, R.W. and Drewes, J.r.E. (2016) rRNA gene expression of abundant and rare activated-sludge microorganisms and growth rate induced micropollutant removal. Environmental Science \& Technology 50(12), 6299-6309.

Ma, J., Dai, R., Chen, M., Khan, S.J. and Wang, Z. (2018) Applications of membrane bioreactors for water reclamation: micropollutant removal, mechanisms and perspectives. Bioresource Technology 269, 532-543.

Griffiths, E. and Gupta, R.S. (2007) Identification of signature proteins that are distinctive of the Deinococcus-Thermus phylum. International Microbiology 10(3), 201.

Mehrshad, M., Salcher, M.M., Okazaki, Y., Nakano, S.-i., Šimek, K., Andrei, A.-S. and Ghai, R. (2018) Hidden in plain sight-highly abundant and diverse planktonic freshwater Chloroflexi. Microbiome 6(1), 176.

Zhang, P., Guo, J.-S., Shen, Y., Yan, P., Chen, Y.-P., Wang, H., Yang, J.-X., Fang, F. and Li, C. (2015) Microbial communities, extracellular proteomics and polysaccharides: A comparative investigation on biofilm and suspended sludge. Bioresource Technology 190, 21-28.

Chen, Y., Lan, S., Wang, L., Dong, S., Zhou, H., Tan, Z. and Li, X. (2017) A review: Driving factors and regulation strategies of microbial community structure and dynamics in wastewater treatment systems. Chemosphere 174, 173-182.

Gumaelius, L., Magnusson, G., Pettersson, B. and Dalhammar, G. (2001) Comamonas denitrificans sp. nov., an efficient denitrifying bacterium isolated from activated sludge. Int J Syst Evol Microbiol 51(3), 999-1006.

Speth, D.R., Guerrero-Cruz, S., Dutilh, B.E. and Jetten, M.S. (2016) Genome-based microbial ecology of anammox granules in a full-scale wastewater treatment system. Nature communications 7, 11172.

Liu, J., Zhang, H., Zhang, P., Wu, Y., Gou, X., Song, Y., Tian, Z. and Zeng, G. (2017) Two-stage anoxic/oxic combined membrane bioreactor system for landfill leachate treatment: Pollutant removal performances and microbial community. Bioresource Technology 243, 738-746.

Gutierrez, T., Rhodes, G., Mishamandani, S., Berry, D., Whitman, W.B., Nichols, P.D., Semple, K.T. and Aitken, M.D. (2014) Polycyclic Aromatic Hydrocarbon Degradation of PhytoplanktonAssociated \&lt;span class=\&quot;named-content genus-species\&quot; id=\&quot;namedcontent-1\&quot;\&gt;Arenibacter\&lt;/span\&gt; spp. and Description of \&lt;span class=\&quot;named-content genus-species\&quot; id=\&quot;named-content2\&quot;\&gt;Arenibacter algicola\&lt;/span\&gt; sp. nov., an Aromatic Hydrocarbon-Degrading Bacterium. Applied and Environmental Microbiology 80(2), 618. 
Sohn, J.H., Kwon, K.K., Kang, J.-H., Jung, H.-B. and Kim, S.-J. (2004) Novosphingobium pentaromativorans sp. nov., a high-molecular-mass polycyclic aromatic hydrocarbon-degrading bacterium isolated from estuarine sediment. Int J Syst Evol Microbiol 54(5), 1483-1487.

Rowan, A.K., Snape, J.R., Fearnside, D., Barer, M.R., Curtis, T.P. and Head, I.M. (2003)

Composition and diversity of ammonia-oxidising bacterial communities in wastewater treatment reactors of different design treating identical wastewater. FEMS Microbiology Ecology 43(2), 195-206.

Chouari, R., Le Paslier, D., Daegelen, P., Ginestet, P., Weissenbach, J. and Sghir, A. (2003)

Molecular Evidence for Novel Planctomycete Diversity in a Municipal Wastewater Treatment Plant. Applied and Environmental Microbiology 69(12), 7354.

Glöckner , F.O., Kube, M., Bauer , M., Teeling, H., Lombardot, T., Ludwig, W., Gade, D., Beck, A., Borzym, K., Heitmann, K., Rabus, R., Schlesner, H., Amann, R. and Reinhardt , R. (2003) Complete genome sequence of the marine planctomycete $<$ em $>$ Pirellula $</ e m>s p$. strain 1 . Proceedings of the National Academy of Sciences 100(14), 8298-8303.

Liu, Y., Jin, J.-H., Liu, Y.-H., Zhou, Y.-G. and Liu, Z.-P. (2010) Dongia mobilis gen. nov., sp. nov., a new member of the family Rhodospirillaceae isolated from a sequencing batch reactor for treatment of malachite green effluent. Int J Syst Evol Microbiol 60(12), 2780-2785.

Huang, J., Yang, X., Wu, Q., Mai, S. and Chi, H. (2019) Application of independent immobilization in benzo[a]pyrene biodegradation by synthetic microbial consortium. Environmental Science and Pollution Research 26(20), 21052-21058.

Eberspächer, J. and Lingens, F. (2006) The Prokaryotes: Volume 5: Proteobacteria: Alpha and Beta Subclasses. Dworkin, M., Falkow, S., Rosenberg, E., Schleifer, K.-H. and Stackebrandt, E. (eds), pp. 250-256, Springer New York, New York, NY.

Green, T.R. and Popa, R. (2012) Enhanced Ammonia Content in Compost Leachate Processed by Black Soldier Fly Larvae. Applied Biochemistry and Biotechnology 166(6), 1381-1387.

He, X.-S., Xi, B.-D., Zhang, Z.-Y., Gao, R.-T., Tan, W.-B., Cui, D.-Y. and Yuan, Y. (2015) Composition, removal, redox, and metal complexation properties of dissolved organic nitrogen in composting leachates. Journal of Hazardous Materials 283, 227-233.

Remmas, N., Melidis, P., Katsioupi, E. and Ntougias, S. (2016) Effects of high organic load on amoA and nirS gene diversity of an intermittently aerated and fed membrane bioreactor treating landfill leachate. Bioresource Technology 220, 557-565.

Carrera, J., Jubany, I., Carvallo, L., Chamy, R. and Lafuente, J. (2004) Kinetic models for nitrification inhibition by ammonium and nitrite in a suspended and an immobilised biomass systems. Process Biochemistry 39(9), 1159-1165.

Xie, B., Lv, Z., Hu, C., Yang, X. and Li, X. (2013) Nitrogen removal through different pathways in an aged refuse bioreactor treating mature landfill leachate. Applied Microbiology and Biotechnology 97(20), 9225-9234.

Terada, A., Sugawara, S., Yamamoto, T., Zhou, S., Koba, K. and Hosomi, M. (2013) Physiological characteristics of predominant ammonia-oxidizing bacteria enriched from bioreactors with different influent supply regimes. Biochemical engineering journal 79, 153-161. 